\title{
Reflections on the Development of Contemporary Ceramic Aesthetics
}

\author{
Yuqian Chen $^{1}$ and Lin Zhou ${ }^{1}$
}

${ }^{1}$ Jingdezhen Ceramic Institute, Jingdezhen, Jiangxi 333403, China

\begin{abstract}
Keywords: Contemporary aesthetics; Environmental aesthetics; Life aesthetics; Integration; Development
\end{abstract}

\begin{abstract}
Life is filled with aesthetics all the time, and "analytic aesthetics" occupies a dominant position in the development of contemporary aesthetics, and environmental aesthetics and life aesthetics have become an important content in the research of contemporary aesthetics. During the process of inheriting and innovating aesthetics in China, while constantly digging the foundation of China's ancient aesthetics, various aesthetic elements against the contemporary globalization background are gradually integrated. There must be a process from conflicts between China's traditional aesthetics and contemporary global aesthetic commonalities to integration, and the integration process and development process are worthy of the reflection of aesthetics masters and contemporary aesthetics and design circles. This paper combines the development trend of contemporary global aesthetics with traditional Chinese ceramic culture to explore the ceramic aesthetic aesthetics and its development trend.

The invention of ceramics has a milestone significance for mankind and promotes the transition from primitive mankind to an advanced civilization. Born in the Yellow River and the Yangtze River Valley, the Chinese nation develops mud, water and fire skills to a new height, and the Chinese porcelain was widely recognized in the world as early as in the ancient times, which was not a recognition of China's ancient porcelain technology, but also a process of spreading China's ceramic culture to the world. Aesthetic thought has a great influence on artistic creation, design and production. Faced with the faster and faster life rhythm and increasingly complex society, people begin to view aesthetics in a new way. Ceramics is a great invention and creation of ancient China with rich philosophical thinking and humanistic atmosphere. The constantly evolving Chinese civilization and accumulation of the ceramic technology are constantly giving new contents to ceramic aesthetics.
\end{abstract}

\section{Development Trend of Contemporary Aesthetics}

After the mid- $20^{\text {th }}$ century, "analytic aesthetics" occupies an important position in the field of global aesthetics and plays a vital role in the development of aesthetics. It is difficult to change this situation. Based on this, views of aesthetics exist in all aspects of art research. And some people even directly regard basic principles of aesthetics as "art philosophy". However, In the analysis and non-analytical methods of research outside the scope of art - the natural and everyday objects of life, two new objects of care just appeared in two aesthetics outside the art. ${ }^{[1]}$

Environmental Aesthetics. The research object of environmental aesthetics is the complex living environment in which human beings are exposed to, thus arousing aesthetic reflection. [2]The impact of the environment on people is also multifaceted, both physically and psychologically. The research object is the influence on people's physical and mental health as well as work efficiency. There are various classifications of environment, and the most important includes the natural environment, cultural atmosphere and urban planning, etc.

In the context of industrialization, any social element can hardly exist independently, so it must actively adapt to the wave of globalization. During the process of urbanization, people gradually abandon the natural and original state of life and enter he mechanical urban life with strong sense of line, fast pace and immobilization. While realizing social development and environment changes, people have to gradually return to a state of self-adaptation between people and the natural environment, which is the evitable result of people's in-depth understanding of the relationship between human beings and nature. Environmental aesthetics should be coordinated with each other 
not only in theory, but also in practical application. Future environmental aesthetics should develop into an ecological aesthetics that involves the organic integration of each part. Human beings are a natural existence in the world, so its relationship with other parts in the world should not be viewed separately. Both continuous and disconnected, social elements and cultural elements, organic elements and inorganic elements should be interdependent and form a continuous balance.

Life Aesthetics. To confirm a work of art, the art work must be put in a specific atmosphere and investigated in a specific history and life, which is a process for art to return to the reality. After hundreds of years of development, the concept of freedom and rationality has been deeply rooted on people's mind in the Western society, and in addition to necessary production and labor, people pursue the beauty of life more, and the concept of art is popularized to a large range. Different from previous society in which art was embodied with special significance and position, in contemporary world, art is gradually related to life. In order to integrate life aesthetics into the entire society, the work center should not be to spread aesthetic concepts to all levels of the contemporary culture through various media, but also extend necessary elements of aesthetics to the entire society both horizontally and vertically. Meanwhile, the boundary between art and non-art tends to blur, which makes people gradually feel that life is art and art is life.

\section{Development Trend of Contemporary Ceramic Aesthetics}

Contemporary ceramic aesthetics cannot be separated from the range of environmental aesthetics and life aesthetics, but contemporary ceramic aesthetics is still rooted deeply in the traditional Chinese culture. On the basis of understanding the traditional Confucianism, Buddhism and Taoism on the aesthetic basis of ceramics, understand the new development of ceramic aesthetics. In the ancient times, Chinese Confucianism and Buddhism had different interpretations of ceramic aesthetics. Confucianism focuses on "ritual", which is embodied in the ceramic, with a magnificent process applied to the ceramic design and production. Taoism's "back to nature" and exploring the originality of things are reflected in the ceramic. Jingdezhen ceramics in the Song Dynasty shows a natural plain, simple feature, and despises the role of carving decoration, and the utensils and nature are closely related as the ideal aesthetic realm. The Buddhism is focused on the empty mood with "complete understanding" as the main way and spirit as a foil to the external environment.

In today's society, with the highly-developed civilization, ceramic design and production has also absorbed the postmodern style, breaking the limits of modernism. A variety of factors are integrated into art works, such as the usage of multiculturalism, materialism, time elements and deconstruction, which makes that there is no fixed form and absolutely unchanged standards of art creation and appreciation due to the constant influence of material culture and historical conditions. This requires ceramic aesthetics to have strong adaptability, adapt to the development trend and integrate environment and life.

Break the Unitarian Aesthetic. In the traditional hierarchical society, the art is monopolized by the upper strata and nobles, and it is difficult to spread among the masses. Aesthetics and art are not directly related to everyday life. ${ }^{[3]}$ In the ceramic culture, the ancient Chinese imperial kiln culture is a complete manifestation of this state. Fine ceramic is royal and aristocratic monopoly, the general public contact with the ceramic is simple decoration simple craft porcelain. It is because of the progress of modern science and technology and the abolition of political privileges, breaking the aesthetic utilitarian, daily life can be filled with aesthetic concepts, and aesthetic is close to the practical objects. In the process of production and promotion of daily porcelain, innovation and pragmatism and fashion elements have been continuously integrated into it, which enriched the connotation of ceramic aesthetics and made full play of the subjective initiative on the basis of predecessors, striving to break the predecessors' restricted area, and thus continue to achieve the quality and art breakthroughs.

Break the Aesthetic Unipolar Pattern. During the development process of Oriental and Western aesthetic culture, there was once a set of value standards for aesthetics. According to the theory of artistic self-discipline: "“Before' and 'after' the modern history dominated by the Europe, art in the contemporary sense is not 'produced', and the art concept of self-discipline was only the 
product of the European culture and the spread to the world." [4] Oriental aesthetic has been within the supervision of official philosophy of Confucianism, and both ceramic designers and producers strictly enforced this set of aesthetic standards. The development of contemporary art must break through these limits so as to make art go to a more open space and integrate art into a country and even the world's culture, breaking the monopoly aesthetic pattern and this is also the development trend of normalizing aesthetic standards after global development. Aesthetics in people's daily life more come from daily experience so as to break the isolation of aesthetic experience, make aesthetic diversified and replace the previously single ceramic aesthetic with ceramic aesthetic from different perspectives. The current development of the ceramic innovation industry fits this point.

III Inheritance and Innovation of Contemporary Ceramic Aesthetics

During the process of actively integrating ceramic aesthetic into the global culture, our country has the responsibility and obligation to protect traditional ceramic culture, so it is necessary to inherit and innovate traditional ceramic aesthetics in contemporary society. In the context of globalization and scientific development, traditional ceramic aesthetic needs to be highly integrated with environmental aesthetics and life aesthetics so as to constantly improve the practicality of ceramics during this process.

Integrate Traditional Ceramic Technology into the Development of Science and Technology. The contemporary ceramic production is gradually transferred from traditional manual production to large machine production in the context of industrialization. Although the progress of science and technology helps ceramic production break the limitation of technical conditions, people's reflection during the process of producing ceramics is also gradually disappearing. In the past, craftsmen sought the unity of craft and aesthetics. It is now an irreversible momentum for scientific and technological progress to promote the development of social productive force, and traditional ceramic technology cannot be independent of modern technology development. China's ancient ceramic artisans accumulated a lot of hand-made porcelain experience, which is the technical foundation for ancient Chinese to explore ceramic aesthetics. However, the design and production of ceramics in ancient times were restricted by technical conditions, and there were some blind points in the exploration of ceramic aesthetics. Contemporary scientific and technological progress can breakthrough these restrictions, and people can re-understand these blind points, make up for the deficiencies of traditional ceramics with scientific and technologic progress and give full play to the unique advantages of China's ceramic aesthetics.

Personalized Development of Ceramic Aesthetics. Contemporary ceramic design is in the constant social development and change, and personalized concept should be the foothold for ceramic artists in creation. Of course, it is necessary to fully consider the environment's adaptability and aesthetic demand and well combine people's subjective initiative with ceramic aesthetics with humanistic care. Among them, it is necessary to fully understand the double meanings of "personalization". On one hand, it is the personalized development of ceramics, which is mainly reflected in various elements: the shape, personalized shape, colors, appearance and decoration; the other is the concept of the big environment including the ceramics' appearance and even the natural and humanistic landscape of the entire ceramic development. [5] Finally, the development of ceramics is to adapt to the demands of social development and integrate people's interpretation of this ethical spirit into the progress and development of the entire society.

The original intention of inventing ceramics is to play the functions of objects. Since ancient times, the element of practicality and whether convenience can be brought to our life should be taken into account in the design and production of most ceramics. After the industrial revolution, ceramic production underwent tremendous changes, and ceramic designers and the mass also think about the practicality of ceramics from a new perspective. The fast-paced, high-pressure, and mechanical sense of contemporary society gives people a sense of fatigue, and practicality cannot just be able to meet people's most common and basic needs. Contemporary ceramic practicality should be more from the ceramic design and takes giving a visual mapping as a starting point.

Therefore, the development of ceramic aesthetics should be in the context of the entire social development with traditional ceramic culture as the basis, science and technology and 
personalization as the path, and the ultimate goal is to make people have better material and spiritual life.

\section{Conclusion}

In the current context of the times with the Sino-foreign ceramic cultural exchanges and rapid international exchange of ceramic products, ceramic aesthetics should carry out the spirit of advancing with the times. Under the development trend of ceramic aesthetic naturalization and life, ceramic aesthetics is naturally developed in ceramic products and cultural exchanges, and is more closely integrated with the times. In the perspective of ceramics, the aesthetic basis of human survival and development is found.

\section{References}

[1] LIU Yuedi. From Contemporary Art, Environmental Aesthetics to Life Aesthetics - on New Trend of Western and Oriental Aesthetics from the 18th World Aesthetics Conference [J]. Hundred Schools of Art, 2010, (5): 35 41.

[2] CHENG Xiangzhan. On the Connection and Difference between Environmental Aesthetics and Ecological Aesthetics [J]. Academic Research, 2013, (1): 122 131.

[3] JI Jing. Comparative Study of "Anesthetization of Daily Life" and "Aesthetic Disinterestedness" [J]. Journal of Heilongjiang Institute of Education, 2009, (2): 128 130.

[4] LIU Yuedi. From Contemporary Art, Environmental Aesthetics to Life Aesthetics - on New Trend of Western and Oriental Aesthetics from the 18th World Aesthetics Conference [J]. Hundred Schools of Art, 2010, (5): 35 41. (5): 35 41.

[5] XIAO Han. On the Application of Modern Aesthetics in Ceramic Design [J]. Jingdezhen Ceramics, 2011, (4):7. 